\title{
Maintaining an Optimal Flow of Forest Products under a Carbon Market: Approximating a Pareto Set of Optimal Silvicultural Regimes for Eucalyptus fastigata
}

\author{
Oliver Chikumbo ${ }^{1}$, Thomas J. Straka ${ }^{2}$ \\ ${ }^{1}$ Scion, Rotorua, New Zealand \\ ${ }^{2}$ Department of Forestry and Natural Resources, Clemson University, Clemson, USA \\ Email: oliver.chikumbo@scionresearch.com
}

Received January $23^{\text {rd }}, 2012$; revised February $24^{\text {th }}, 2012$; accepted March $17^{\text {th }}, 2012$

\begin{abstract}
A competitive co-evolutionary Multi-Objective Genetic Algorithm (cc-MOGA) was used to approximate a Pareto front of efficient silvicultural regimes for Eucalyptus fastigata. The three objectives to be maximised included, sawlog, pulpwood and carbon sequestration payment. Three carbon price scenarios (3CPS), i.e. NZ $\$ 25, \mathrm{NZ} \$ 50$ and $\mathrm{NZ} \$ 100$ for a tonne of $\mathrm{CO}_{2}$ sequestered, were used to assess the impact on silvicultural regimes, against a fourth non-carbon Pareto set of efficient regimes (nonCPS), determined from a cc-MOGA with two objectives, i.e. competing sawlog and pulpwood productions. Carbon prices included in stand valuation were found to influence the silvicultural regimes by increasing the rotation length and lowering the final crop number before clearfell. However, there were no significant changes in the frequency, timing, and intensity of thinning operations amongst all the four Pareto sets of solutions. However, the 3CPS were not significantly different from each other, which meant that these silvicultural regimes were insensitive to the price of carbon. This was because maximising carbon sequestration was directly related to the biological growth rate. As such an optimal mix of frequency, intensity, and timing of thinning maintained maximum growth rate for as long as possible for any one rotation.
\end{abstract}

Keywords: Optimal Control; Competitive Co-Evolutionary Multi-Objective Genetic Algorithm (cc-MOGA); Pareto Front; Forest Holding Value; Kruskal-Wallis Test; Multiple Comparison Procedure

\section{Introduction}

The central focus of our analysis was to approximate a set of optimal silvicultural regimes for a Eucalyptus fastigata forest stand under a carbon market. Each estimated regime was expressed as a set of values that included an initial planting stocking, frequency of thinning, timing of thinning, intensity of thinning, final crop number prior to clear-felling, and rotation length. We, therefore, crafted a three-objective optimisation problem, which simultaneously maximised, sawlog, pulpwood and carbon sequestration payment (under three different payment scenarios). This optimisation problem, described later, was based on a two-objective optimisation problem that was successfully solved by simultaneously optimising competing sawlog and pulpwood products (Chikumbo \& Nicholas, 2011). The results from the two-objective and three-objective optimisation runs were statistically analysed to decipher the nuances of silvicultural strategies under a carbon market.

\section{Assumptions and Forest Holding Value}

To carry out the analysis, we assumed fixed prices for liquid fuels and fossil fuel-based fertilisers such that the carbon price would remain static over the rotation period. This assumption was based on the observation of the EU Emissions Trading Scheme where the carbon price was heavily influenced by fossil fuel prices, which tend to be volatile (White, 2007). The carbon price would in turn influence the forest holding value, and ultimately impact the stand silvicultural regimes of $E$. fastigata. Forest holding values enable valuation of timber as real property, where timber for immediate harvesting has a liquidation value and the immature resource has a holding value (Mayo \& Straka, 2007).

Any forest has an immediate liquidation value if the existing timber is clearfelled and sold along with the land. The forest holding value is the present value of holding the forest until the optimal rotation age (maximum present value) and then selling the timber and land (Klemperer, 1996). The concept is consistent with standard forestry valuation concepts such as land expectation value (Faustmann, 1995; De Jong, Tipper \& Montoya-Gómez, 2000). Note that the forest is financially immature for as long as the forest holding value exceeds the forest liquiddation value. Therefore, the rotation age should be allowed to increase until the two values are equal (Mayo \& Straka, 2007). Thus, the forest holding value provides an ideal financial criterion to evaluate the impact of carbon sequestration payments on the optimal rotation length.

\section{Contribution to Forest Literature}

There is an expectation that any forester/land owner wishing to engage in forest-carbon trading, in order to take advantage of a new income stream from carbon sequestration, would want to know the ideal/optimal silvicultural regimes for his/her crop that will not only maximise carbon sequestration (for maximum 
pay out), but also maximise production of sawlog and/or pulpwood (De Jong, Tipper \& Montoya-Gómez, 2000). However, we do know that many forest analysts have shown that increasing the rotation length would be the sensible thing to do (Appel, 2001; Asante, Armstrong \& Adamowicz, 2011; Gutrich \& Hoswarth, 2007). What is scarce in literature is:

1) How the frequency, intensity and timing of thinning for a silvicultural regime are affected;

2) Whether the longer rotation length is linked to a higher or relatively lower final crop number before clearfell;

3) The ability to simultaneously cater for pulpwood and sawlog products under a prevailing carbon market from a single regime instead of different regimes where each specifically caters for a unique product; and

4) How the silvicultural regimes are affected by different carbon prices.

Our paper addresses these issues. The specifics of determineing the optimal initial planting stocking, optimal rotation length, frequency, timing and intensity of thinning, tree species and site, have been modeled by forest analysts using multi-stage optimisation since the 60s' (Hool, 1965), with mixed successes. The reasons for these mixed successes boiled down to the use of inappropriate growth functions, and an inability to do an exhaustive search for all possible states in a dynamic programming formulation (Chikumbo, 1996; Chen, Rose \& Leary, 1980). Bellman (1957) coined this exhaustive search problem, the "curse of dimensionality".

\section{Historical Background of Problem Solving}

A pulpwood production was characterised by short rotations and a relatively longer rotation with thinning (i.e., partial harvesting) for a sawlog production regime (Newman \& Wear, 1993). To overcome the curse of dimensionality, the determination of optimal silvilcultural regimes for separate pulpwood and sawlog production was pursued using a specialised mathematical formulation, i.e. a combined optimal control and optimal parameter selection optimisation (Chikumbo \& Mareels, 2003). The growth dynamics of a tree crop stand were described with difference equations in discrete-time and the complete mathematical formulation was as follows:

$$
\underset{\boldsymbol{u}, z}{\operatorname{minimise}}\left\{\begin{array}{l}
J_{0}(\boldsymbol{u}, z)=\phi_{0}(\boldsymbol{x}(T), z) \\
+\sum_{t=0}^{T} j_{0}(t, \boldsymbol{x}(t), \boldsymbol{u}(t), z)
\end{array}\right\}
$$

subject to the growth dynamics,

$$
\boldsymbol{x}(t+1)=\boldsymbol{f}(t, \boldsymbol{x}(t), \boldsymbol{u}(t), z),(\text { which is the state variable }),
$$

where,

$J_{0}=$ the cost functional (i.e. a function of state and control variables or simply the objective function);

$\phi_{o}=$ continuously differentiable function;

$j_{0}=$ continuously differentiable function with respect to the state and control variables;

$t=0,1, \cdots, T-1$ (for time in years);

$T=$ rotation age; and

$z=$ estimated parameter(s) independent of time,

$$
\boldsymbol{u}(t)=\left[u_{1}(t), \cdots u_{T}(t)\right]
$$

which represented the control vector over the rotation length at one year intervals expressed as the number of trees harvested per hectare, i.e.

$$
\operatorname{sph}(t)=\operatorname{sph}(t-1)-u_{i}(t-1),
$$

where, $\operatorname{sph}(t)=$ the number of standing trees at time, $t$, and

$$
u_{i}^{L}(t) \leq u_{i}(t) \leq u_{i}^{U},
$$

where for each $u_{i}$, there are Lower and Upper bounds.

The state variable consisted of the mean stand height, which was the mean height in metres per hectare $(\operatorname{mht} t(t))$, the stand basal area in square metres per hectare $(s b a(t))$, and stand volume in cubic metres per hectare $(\operatorname{vol}(t))$, i.e.

$$
\boldsymbol{x}(t)=\left[\begin{array}{c}
m h t(t) \\
\operatorname{sba}(t) \\
\operatorname{vol}(t)
\end{array}\right],
$$

where,

$$
\begin{aligned}
& m h t(t)=a_{1}^{m h t} m h t(t-1)+a_{2}^{m h t} m h t(t-2)+b^{m h t}, \\
& a_{1}^{m h t}=f(\operatorname{sph}(t)), a_{2}^{m h t}=f(\operatorname{sph}(t)), \\
& b^{m h t}=f(\operatorname{sph}(t)),
\end{aligned}
$$

was a discrete-time dynamical model/difference equation (Ljung, 1987) of mean stand height with parameters, $a_{1}^{m h t}, a_{2}^{m h t}$, and $b^{m d h}$ and that were functions of the number of standing trees, $\operatorname{sph}(t)$

$$
\begin{aligned}
& s b a(t)=a_{1}^{s b a} \operatorname{sba}(t-1)+a_{2}^{s b a} \operatorname{sba}(t-2)+b^{s b a}, \\
& a_{1}^{s b a}=f(\operatorname{sph}(t)), a_{2}^{s b a}=f(\operatorname{sph}(t)), \\
& b^{s b a}=f(\operatorname{sph}(t)),
\end{aligned}
$$

the stand basal area, also a discrete-time dynamical model with parameters $a_{1}^{s b a}, a_{2}^{s b a}$, and $b^{s b a}$ that were functions of the number of standing trees, $\operatorname{sph}(t)$,

$$
\begin{aligned}
& \operatorname{vol}(t)=a_{1}^{\text {vol }} \operatorname{vol}(t-1)+a_{2}^{\text {vol }} \operatorname{vol}(t-2)+b^{\text {vol }}, \\
& a_{1}^{\text {vol }}=f(\operatorname{sph}(t)), a_{2}^{\text {vol }}=f(\operatorname{sph}(t)), \\
& b^{\text {vol }}=f(\operatorname{sph}(t)),
\end{aligned}
$$

the stand volume function, a discrete-time dynamical model with parameters, $a_{1}^{v o l}, a_{2}^{v o l}$, and $b^{\text {vol }}$ that were functions of the number of standing trees, $\operatorname{sph}(t)$,

$$
z=\left[z_{\text {sph }\left(t_{0}\right)}, z_{T}\right]
$$

the system parameters independent of time,

where,

$$
z_{s p h\left(t_{o}\right)}=\text { estimated initial planting stocking; and }
$$

$z_{T}=$ estimated rotation length,

subject to Lower and Upper bounds,

$$
z_{l s p h\left(t_{0}\right)}^{L} \leq z_{\operatorname{sph}\left(t_{0}\right)} \leq z_{\operatorname{sph}\left(t_{0}\right)}^{U}, \text { and } z_{T}^{L} \leq z_{T} \leq z_{T}^{U}
$$

The problem (1)-(10) was solved using Pontryagin's Maximum Principle (PMP) (Chikumbo \& Mareels, 2003). Only a single objective problem was solved at any one time, i.e. either a value production or a volume production cost functional. It is possible to solve a multi-objective optimal control problem using PMP (Malinowska \& Torres, 2007) for a finite number of cost functionals, but this was never meant to be because of one problem. Trying to estimate the optimal rotation length as a system parameter led to ill-conditioning (i.e. an accumulation 
of round-off errors from a sequence of matrix inversions that are numerically unstable and that may result in meaningless solutions). We will call this the phase-1 ill-conditioning. The stopgap measure was to solve a series of combined optimal control and a single optimal selection problem (i.e. the initial planting stocking), with a fixed $T$ at increasing intervals, so as to locate the optimal rotation length. Optimal $T$ was the point at which a unit increment in $T$ resulted in "phase-2 ill-conditioning", caused by growth dynamics that could not perform outside their range. The whole process was time-consuming, giving a clear signal that a better way had to be found.

\section{Research Focus and Problem Solving}

A switch to a single objective genetic algorithm eliminated the phase-1 ill-conditioning problem (Chikumbo, 2009a). Chikumbo and Nicholas (2011) demonstrated a two-objective genetic algorithm that simultaneously optimised for a value and volume production for Eucalyptus fastigata. Figure 1 shows a summary of a generic genetic algorithm and how it works.

A genetic algorithm is initialized with a population of randomly generated individuals which is a guided process of "selection", "crossover/recombination" and "mutation". Individuals are selected on the basis of their fitness for reproduction. The parent individuals are recombined to produce offspring where only some of them are mutated with a certain probability. The fitness of the offspring is then computed, resulting in the parents being replaced, thus producing a new generation. If the criteria of the objective function(s) are not met, this cycle is performed again until the optimisation criteria are reached (Polheim, 2006).

Therefore, a set of efficient silvicultural regimes that satisfied carbon sequestration payments, sawlog/value production, and pulpwood/volume production at different levels of "tradeoffs" was estimated using genetic algorithms, eliminating the need for determining separate regimes for sawlog and pulpwood under a carbon market. Such regimes give the forester/ land owner the ability to satisfy the market with all products whilst maximizing carbon sequestration payments, with the flexibility of meeting an increased/decreased supply of any one of the products as dictated by demand.
The critical part of approximating the set of efficient thinning regimes was to find "trade-off" solutions (i.e. non-dominated solutions) where for each solution an improvement in one objective did not lead to worsening in the other (Osborne \& Rubenstein, 1994). The set of solutions to the three-objective problem was determined using a competitive co-evolutionary genetic algorithm with five subpopulations of 100 individuals each, computed over 1000 generations. These sub-populations evolved independently for a certain number of generations (isolation time). After the isolation time a number of individuals were distributed between the sub-populations (a process called migration). Each sub-population exerted selective pressure on the other, thereby maintaining diversity a lot longer than each sub-population would do solitarily, thereby guarding against premature convergence. When competition was superimposed between the sub-populations, the ones with higher mean fitness values were allowed to maintain larger sub-population sizes and received more capable individuals, since they had more chances of finding the global optimum (Chikumbo, 2009b; Chikumbo, 2012).

The Fonseca and Fleming ranking scheme (Fonseca \& Fleming, 1993) was used to determine the non-dominated solutions, also referred to as the Pareto front. A conflict in the objectives results in a trade-off set (i.e. Pareto), which means that the solutions in the set are optimal in the wider sense that no other solutions in the search space are superior to them when all the objectives are considered.

Fonseca and Fleming called their ranking scheme, MultiObjective Genetic Algorithm (MOGA) and it involves assigning an individual's rank (in the objective function space) equal to the number of population individuals that dominated that individual. What this means is that ranking of the individuals prior to selection for recombination is done according to the degree of domination; the more members of the current population that dominate a particular individual, the lower its rank. MOGA, therefore, uses fitness sharing in the objective function space and recombination is also restricted. Reproduction probabilities are determined by means of exponential ranking. Afterwards the fitness values are averaged and shared among individuals having identical ranks (Zitler, Deb, \& Thiele, 2000). Finally, stochastic universal sampling, which provides zero bias

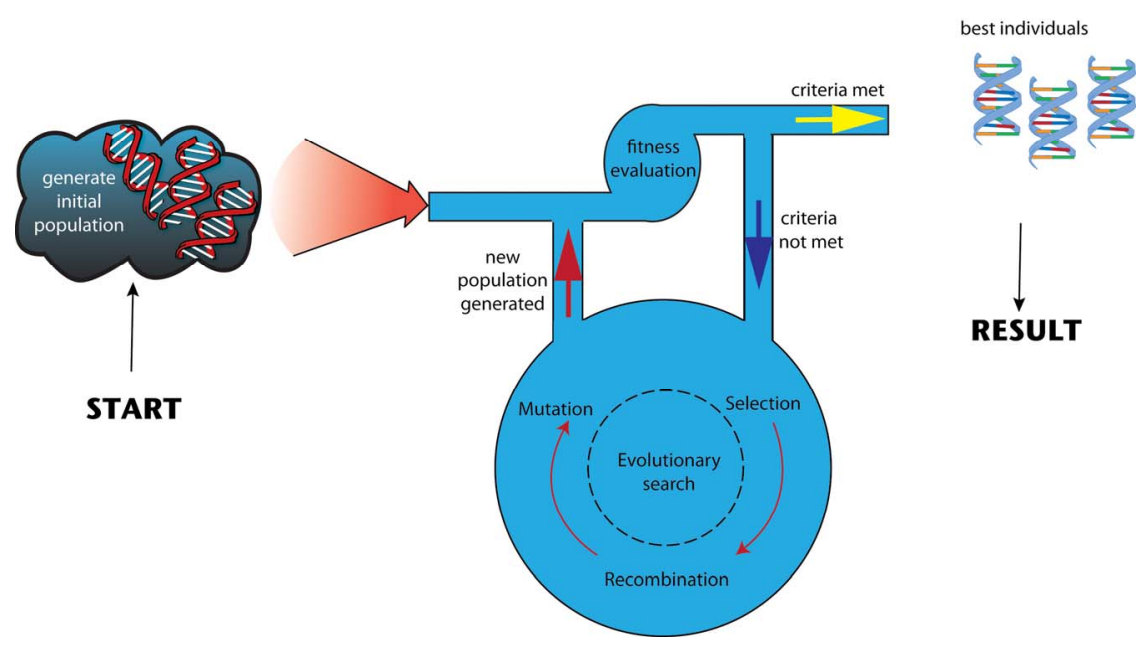

Figure 1.

Genetic algorithm search that mimics evolutionary processes to solve optimisation problems (diagram from (Chikumbo, 2012)). 
and minimum spread (i.e. the range of possible values for the number of offspring of an individual), is used to fill the sampling pool. The main strength of MOGA is that it is efficient and relatively easy to implement. It has also been successfully implemented in solving optimal control problems with good overall performance (Coello, 1996).

In this paper we follow the formulation by (Chikumbo \& Nicholas, 2011), a competitive co-evolutionary Multi-Objective Genetic Algorithm (cc-MOGA), but with an additional objective, i.e. maximisation of carbon sequestration payment. We focus on the threeobjectives and the forest holding values (held static because of the assumption of fixed prices of liquid fuel and fossil fuel-based fertilisers) on how they are formulated and discuss the results of the three-objective cc-MOGA. The same species, E. fastigata, and growth functions by (Chikumbo \& Nicholas, 2011) are used in our analysis.

\section{Data}

First, E. fastigata Deane \& Maiden is considered to be the most suitable eucalypt for a wide range of sites in New Zealand because it has a wide site tolerance, performing well from near sea level to altitudes up to $500 \mathrm{~m}$ (Chikumbo \& Nicholas, 2011). It can be utilised for solid timber as well as providing short-fibre pulp for the production of fine printing paper (Miller, Hay, \& Ecroyd, 2000; Haslett, 1988).

The data used for the growth dynamics of E. fastigata came from a 1979 Nelder trial (Nelder, 1962) established in Kaingaroa Forest (latitude $38^{\circ} 27.6^{\prime} \mathrm{S}$, longitude $176^{\circ} 39.9^{\prime} \mathrm{E}$ and an altitude of $280 \mathrm{~m}$ ), near Murupara, New Zealand. A Nelder trial consists of trees planted in a series of concentric circles where the growing space available to each tree is determined by the distance to the nearest eight neighbouring trees.

Further detail on the trial is found in (Chikumbo \& Nicholas, 2011) and the summary of the data is shown in Table 1. The costs and revenue for silvicultural treatments used in determining forest holding values for the valuation of timber products and carbon sequestered were obtained from (Turner, West, Dungey, Wakelin, Maclaren, Adams \& Silcock, 2008).

\section{The Model}

There were two main reasons why cc-MOGA was used to solve the three-objective optimisation problem:

1) A competitive co-evolutionary genetic algorithms maintains diversity and controls the selective pressure by balancing

Table 1.

Summary of the 286 data points measured from the Nelder trial (Chikumbo \& Nicholas, 2011).

\begin{tabular}{|c|c|c|c|}
\hline & Minimum & Mean & Maximum \\
\hline Age (years) & 3.4 & 12.2 & 28.7 \\
\hline $\mathrm{SPH}\left(\right.$ stems $\left.\cdot \mathrm{ha}^{-1}\right)$ & 89 & 1181 & 4356 \\
\hline $\mathrm{DBH}^{*}(\mathrm{~cm})$ & 3.6 & 20.4 & 61.7 \\
\hline $\mathrm{MD}^{\#}(\mathrm{~cm})$ & 4.2 & 28.1 & 62.6 \\
\hline Mean stand height ${ }^{\sim}(\mathrm{m})$ & 3.6 & 18.7 & 42.8 \\
\hline Stand basal area $\left(\mathrm{m}^{2} \cdot \mathrm{ha}^{-1}\right)$ & 0.1 & 28.1 & 113.6 \\
\hline Stand volume $\left(\mathrm{m}^{3} \cdot \mathrm{ha}^{-1}\right)$ & 0.2 & 182.1 & 1075.2 \\
\hline $\begin{array}{l}\text { Volume mean annual } \\
\text { increment }\left(\mathrm{m}^{3} \cdot \mathrm{ha}^{-1} \cdot \text { year }^{-1}\right)\end{array}$ & 0.1 & 12.1 & 40.2 \\
\hline
\end{tabular}

"Diameter at breast height measured at $1.4 \mathrm{~m}$; ${ }^{*}$ Mean of 100 largest diameter trees per hectare; $\sim$ Mean height of 100 largest diameter trees per hectare. exploration and exploitation in the search space, in a way that avoids premature convergence (Chikumbo, 2009b; Menczer, Degeratu, \& Street, 2000); and

2) Splitting the population into diverse sub-populations that communicate through migration may result in parallel speedups (Menczer, Degeratu, \& Street, 2000).

The three objectives or cost functionals were as follows:

$$
\begin{gathered}
J_{n}(u)^{1}=\max _{u((t)} \sum_{t=T-(n-1)}^{T} \frac{u(t)}{\operatorname{sph}(t)} * \operatorname{sba}(t) * \ldots \\
m h t(t) * f h v_{N Z D 100}(t) * \frac{\operatorname{vol}(t)}{\operatorname{sph}(t)}
\end{gathered}
$$

for value production;

$$
\begin{gathered}
J_{n}(u)^{2}=\max _{u(t)} \sum_{t=T-(n-1)}^{T} \frac{u(t)}{\operatorname{sph}(t)} * s b a(t) * \ldots \\
m h t(t) * f h v_{N Z D 100}(t),
\end{gathered}
$$

for volume production; and

$$
\begin{aligned}
J_{n}(u)^{3} & =\max _{u((t)} \sum_{t=T-(n-1)}^{T} \frac{(\operatorname{sph}(t)-u(t))}{\operatorname{sph}(t)} * C_{f} \ldots \\
& * \operatorname{vol}(t) * f h v_{c}(t),
\end{aligned}
$$

for carbon sequestration payments.

subject to the constraints,

$$
t \geq T-(n-1)
$$

with upper and lower bounds on the control:

$$
\begin{aligned}
& 0 \leq u(t) \leq 300, \forall t \in\left[t_{1}, t_{2}\right], \\
& 0 \leq u(t) \leq 200, \forall t \in\left[t_{3}, t_{4}\right],
\end{aligned}
$$

and

$$
0 \leq u(t) \leq 200, \forall t \in\left[t_{5}, t_{6}\right],
$$

where,

$t_{1}-t_{2}=5-10$ year time window for an initial thinning;

$t_{3}-t_{4}=12-15$ year time window for a second thinning;

$t_{5}-t_{6}=18-21$ year time window for a third thinning;

$T=$ rotation length;

$f v h_{N Z D 100}(t)=$ the forest holding value at time $t$ for sawlogs;

$f v h_{N Z D 20}(t)=$ the forest holding value at time $t$ for pulpwood;

$f v h_{C}(t)=$ the forest holding value at time $t$ for carbon sequestered; and

$C_{f}=$ a factor of 0.23 that converts total carbon sequestered $\left(\mathrm{tCO}_{2} \cdot \mathrm{m}^{-3}\right)$ from total stand volume (Meade, Fiuza, \& Lu, 2008).

The two-parameter selection constraints were formulated as follows:

$$
900 \leq \operatorname{sph}\left(t_{0}\right) \leq 2000,
$$

for the initial planting stock, and

$$
25 \leq T \leq 35,
$$

for the rotation length, where $t_{0}$ is the initial time.

As for the multi-objective problem with the three cost functionals, $J_{n}(u)^{1}, J_{n}(u)^{2}$, and $J_{n}(u)^{3}$, there exists no solution pair $(\boldsymbol{x}$, $\boldsymbol{u})$ that renders a global minimum value to each of the functionals simultaneously. Rather, there exists a finite set of solutions that represent trade-offs. A key concept in determining this set of solutions is that of Pareto optimality: 
Assume two solutions $(\mathbf{x}, \mathbf{u}),\left(\mathbf{x}^{\prime}, \mathbf{y}^{\prime}\right) \in \Omega$, where $\Omega$ is denoted as the solution space. Then $(\mathbf{x}, \mathbf{u})$ is said to dominate $\left(\mathbf{x}^{\prime}, \mathbf{y}^{\prime}\right)$ (also written $\left.(\mathbf{x}, \mathbf{u}) \succ\left(\mathbf{x}^{\prime}, \mathbf{y}^{\prime}\right)\right)$ iff

$$
\begin{aligned}
& \forall i \in\{1,2, \cdots, n\}: J_{i}(\boldsymbol{X}, \boldsymbol{U}) \geq J_{i}\left(\boldsymbol{X}^{\prime}, \boldsymbol{U}^{\prime}\right) \wedge \\
& \exists m \in\{1,2, \cdots, n\}: J_{m}(\boldsymbol{X}, \boldsymbol{U})>J_{m}\left(\boldsymbol{X}^{\prime}, \boldsymbol{U}^{\prime}\right) .
\end{aligned}
$$

However, $(\mathbf{x}, \mathbf{u})$ is said to cover $\left(\mathbf{x}^{\prime}, \mathbf{u}^{\prime}\right)\left((\mathbf{x}, \mathbf{u}) \succ\left(\mathbf{x}^{\prime}, \mathbf{u}^{\prime}\right)\right)$ iff

$$
\begin{aligned}
& \forall i \in\{1,2, \cdots, n\}: J_{i}(\boldsymbol{X}, \boldsymbol{U}) \leq J_{i}\left(\boldsymbol{X}^{\prime}, \boldsymbol{U}^{\prime}\right) \wedge \\
& \exists m \in\{1,2, \cdots, n\}: J_{m}(\boldsymbol{X}, \boldsymbol{U})<J_{m}\left(\boldsymbol{X}^{\prime}, \boldsymbol{U}^{\prime}\right) .
\end{aligned}
$$

In this case $(\mathbf{x}, \mathbf{u})$ is non-dominated by $\left(\mathbf{x}^{\prime}, \mathbf{y}^{\prime}\right)$.

Therefore, the set of non-dominated solutions, $\Omega^{N}$, within the entire search space, $\Omega$, is called the Pareto optimal set.

\section{Forest Holding Value and Carbon Sequestration Accounting}

The valuation of timber for a stand defined as $f v h_{N Z D 100}(t)$, $f v h_{N Z D 20}(t)$ and $f v h_{C}(t)$ in the cost functionals (11)-(13), were based on the forest holding value. The holding value is defined as follows:

$$
F V H(t)=P V H(t)-P V_{\text {costs }}-\text { LOC, }
$$

where,

$F V H(t)=$ holding value at time, $t$

$P V H(t)=$ Discounted present value of optimal harvest at time, $t$

$P V_{\text {costs }}=$ Discounted costs at time $t ;$ and

$L O C=$ Land opportunity cost.

At any point in time carbon sequestered is a function of the change in biomass and the amount of carbon per $\mathrm{m}^{3}$ of biomass. It is not just the age of the trees per se or standing timber volume that is important, but rather the rate of tree growth (van Kooten, Binkley \& Delcourt, 1995). As trees grow they sequester carbon, but once carbon has been sequestered no further benefits are forthcoming. In other words the income generated by sequestering carbon at time, $t$ is the value of the extra amount of carbon sequestered between $t$ and $t-1$ multiplied by the price of carbon, as shown in the following equation:

$$
S_{\S}^{t-(t-1)}(t)=P c *(S(t)-S(t-1)),
$$

where,

$S_{\$}^{t-(t-1)}(t)=$ Carbon sequestration payment at time, $t$;

$P c=$ Price for sequestering carbon $\left(\$ \cdot \mathrm{m}^{-3}\right)$;

$S(t)=$ Total carbon sequestered at time, $t$, for a stand; and

$S(t-1)=$ Total carbon sequestered at time, $(t-1)$.

The present value of the above equation at the time of planting the crop then becomes:

$$
P V_{\text {card }}(t)=\frac{S_{\$}^{t-(t-1)}}{(1+r)^{t}}
$$

where,

$P V_{\text {carb }}(t)=$ Discounted carbon sequestration payment at time, $t$.

Therefore, the forest holding value that includes carbon sequestration payments then takes the following form:

$$
F V H(t)=P V H(t)+P V_{\text {carb }}(t)-P V_{\text {costs }}-L O C
$$

An assumption was implicit in the calculation that there was a zero harvesting emissions liability. All it meant was that there was no carbon sequestration payment for the proportion of harvested timber through thinning or clearfelling.

\section{Results and Discussion}

The results of the two-objective optimisation problem with the objectives (11) and (12) for value and volume products are shown in Table 2 with only 6 regimes included in the Pareto set. The other Pareto sets for the three carbon prices scenarios, NZ \$25, NZ \$50, and NZ \$100, are shown in Appendices A (Table A1), B (Table B1), and C (Table C1), because of the larger size of their sets, at 30, 30, and 29 regimes respectively.

All these results in Tables 1, A1, B1 and C1 were not averaged, as this would defeat the purpose of finding a Pareto set of solutions in the first place. Therefore, investigating the impact of carbon prices on the silvicultural regimes of E. fastigata involved comparisons of the Pareto sets using the Kruskal-Wallis test (Kruskal \& Wallis, 1952). This is a non-parametric version of the classical one-way analysis of variance and an extension of the Wilcoxon rank sum test (Gibbons 1985), specifically for testing equality of population medians among groups (which in our case are the four scenarios in Tables 1, A1, B1 and C1). Ordering the data from smallest to largest across all groups and taking the numeric index of this ordering determines the ranks.

\section{Initial Planting Stocking}

A $p$-value of 0.4018 suggests that we accept the null hypothesis that the initial planting stockings from the different groups have the same mean. The box plots in Figure 2 confirm this with the overlap of the medians at one standard deviation of the group means. The Wilcoxon rank sum test, plotted in Figure 3, shows more clearly the degree of overlap and no

\begin{tabular}{|c|c|c|c|c|c|c|c|c|}
\hline REGIME & $\begin{array}{c}\text { Age at T1 } \\
(\mathrm{yrs})\end{array}$ & $\begin{array}{c}\text { Age at T2 } \\
(\mathrm{yrs})\end{array}$ & $\begin{array}{c}\text { Age at T3 } \\
(\mathrm{yrs})\end{array}$ & $\begin{array}{c}\text { Clear felling age } \\
(y r s)\end{array}$ & $\begin{array}{l}\text { Init. stocking } \\
\left(\text { stems } \cdot \mathrm{ha}^{-1}\right)\end{array}$ & $\begin{array}{c}\mathrm{T} 1 \\
\left(\mathrm{stems} \cdot \mathrm{ha}^{-1}\right)\end{array}$ & $\begin{array}{c}\mathrm{T} 2 \\
\left(\mathrm{stems} \cdot \mathrm{ha}^{-1}\right)\end{array}$ & $\begin{array}{c}\mathrm{T} 3 \\
\left(\text { stems } \cdot \mathrm{ha}^{-1}\right)\end{array}$ \\
\hline 1 & 5 & 13 & 20 & 35 & 988 & 287 & 153 & 196 \\
\hline 2 & 5 & 15 & 18 & 35 & 995 & 274 & 168 & 186 \\
\hline 3 & 5 & 15 & 20 & 35 & 936 & 259 & 196 & 170 \\
\hline 4 & 5 & 14 & 19 & 35 & 939 & 240 & 190 & 176 \\
\hline 5 & 5 & 15 & 18 & 35 & 937 & 234 & 185 & 197 \\
\hline 6 & 5 & 12 & 18 & 35 & 903 & 228 & 193 & 187 \\
\hline
\end{tabular}
statistical difference between the initial planting stockings of the different groups. We conclude here that different carbon prices do not seem to have an impact on the initial planting stocking of E. fastigata.

Table 2.

Thinning regimes (showing number of trees thinned at T1, T2 and T3) for E. fastigata derived from a two-objective optimisation problem with objectives, sawlog (value) and pulpwood (volume) productions (Chikumbo \& Nicholas, 2011). 


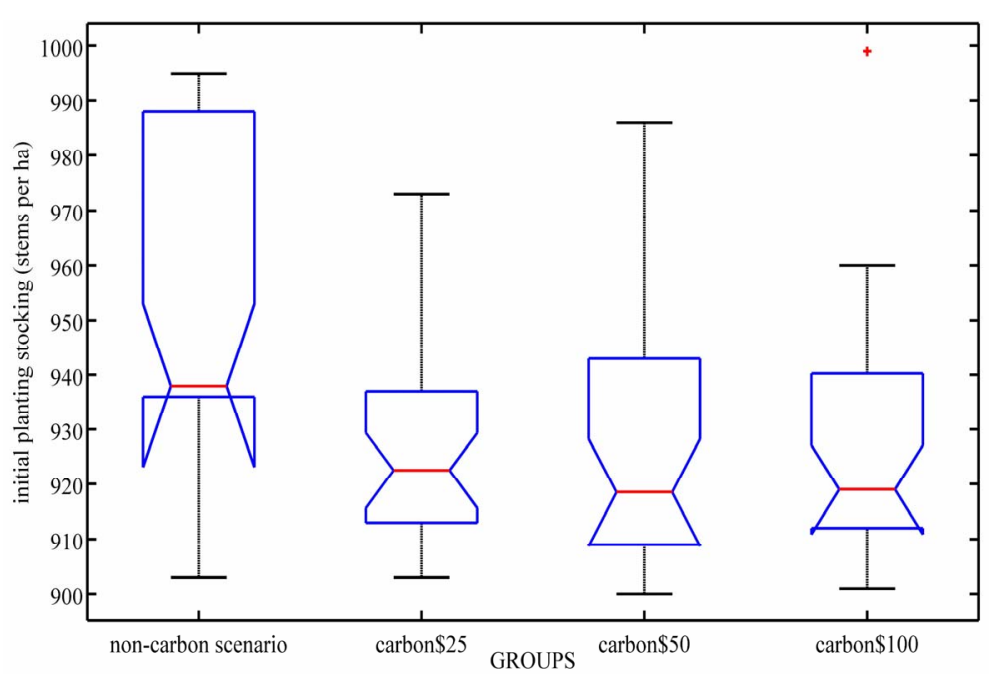

Figure 2.

Box plots of the four scenarios where, the central mark in each box is the median; the edges of the box are the 25th and 75th percentiles; the notches in the boxes represent one standard deviation of the mean; the ends of the whiskers are the minimum and maximum; and outliers are plotted individually with the "+" sign.

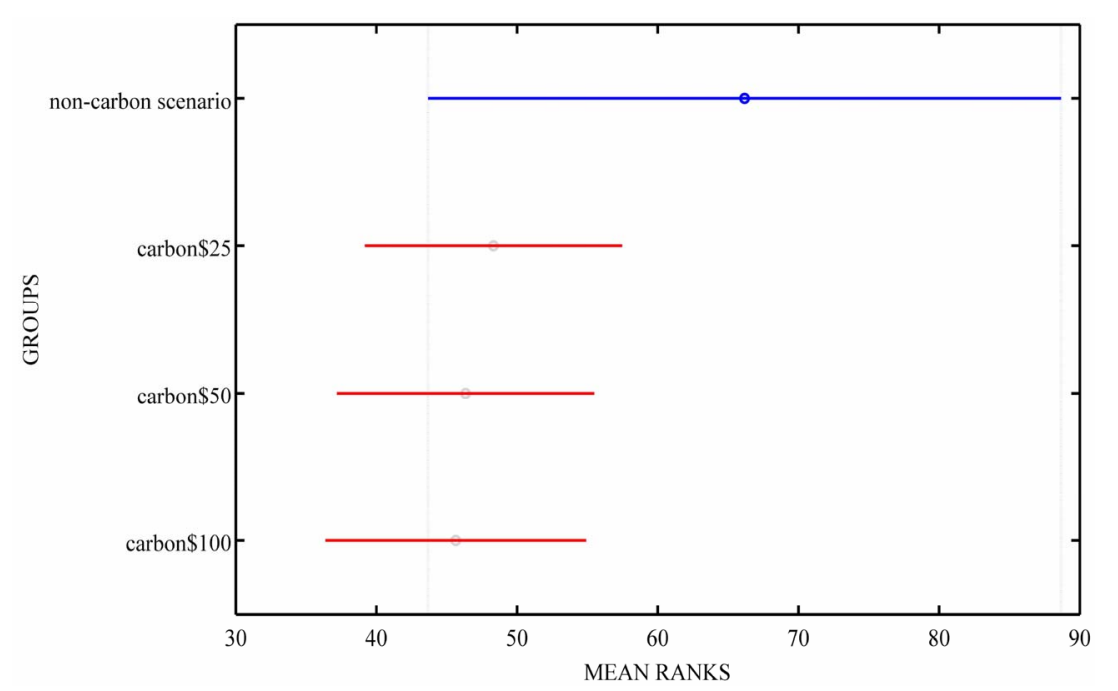

Figure 3.

Wilcoxon rank sum test for the initial planting stockings of the different groups/scenarios.

\section{Final Crop Number}

A $p$-value of 0.0014 suggested that there were differences between the groups as shown in the box plots in Figure 4. The non-carbon scenario showed a higher number of retained crops before final harvesting, than all the carbon scenarios, which showed an overlap of the one standard deviation of their final crop numbers. The mean ranking in Figure 5 showed more clearly the degree of overlap among the three carbon scenarios.

\section{Rotation Length}

There was also a difference in the rotation length medians amongst the different groups with a $p$-value of 0.003 . The non-carbon scenario showed no variation in the rotation length, which remained at 35 years for all the individual regimes in the Pareto set, whereas the other three carbon scenarios had higher medians, which overlapped at one standard deviation of the medians. The summary is shown in Figure 6. The summary of the mean ranks of the rotation lengths in Figure 7 confirmed the differences between the non-carbon scenario with a lower rotation length, and the three carbon scenarios with higher ranges of rotation lengths. This observation agrees with conventional wisdom that rotation lengths will be longer in order to sequester more carbon. What is interesting with our results here is that the rotation lengths are insensitive to the variations in the carbon price.

We assert that this insensitivity to the price of carbon is because our optimisation model is maxing out the sequestration of carbon as much as the equations for the growth dynamics of E. fastigata will allow. This is good news for the forester, in that for any forest signed up to an emissions trading scheme, there is only one set of optimal regimes to consider that will simultaneously satisfy a sawlog and pulpwood market, regardless of fluctuations in the carbon price. 


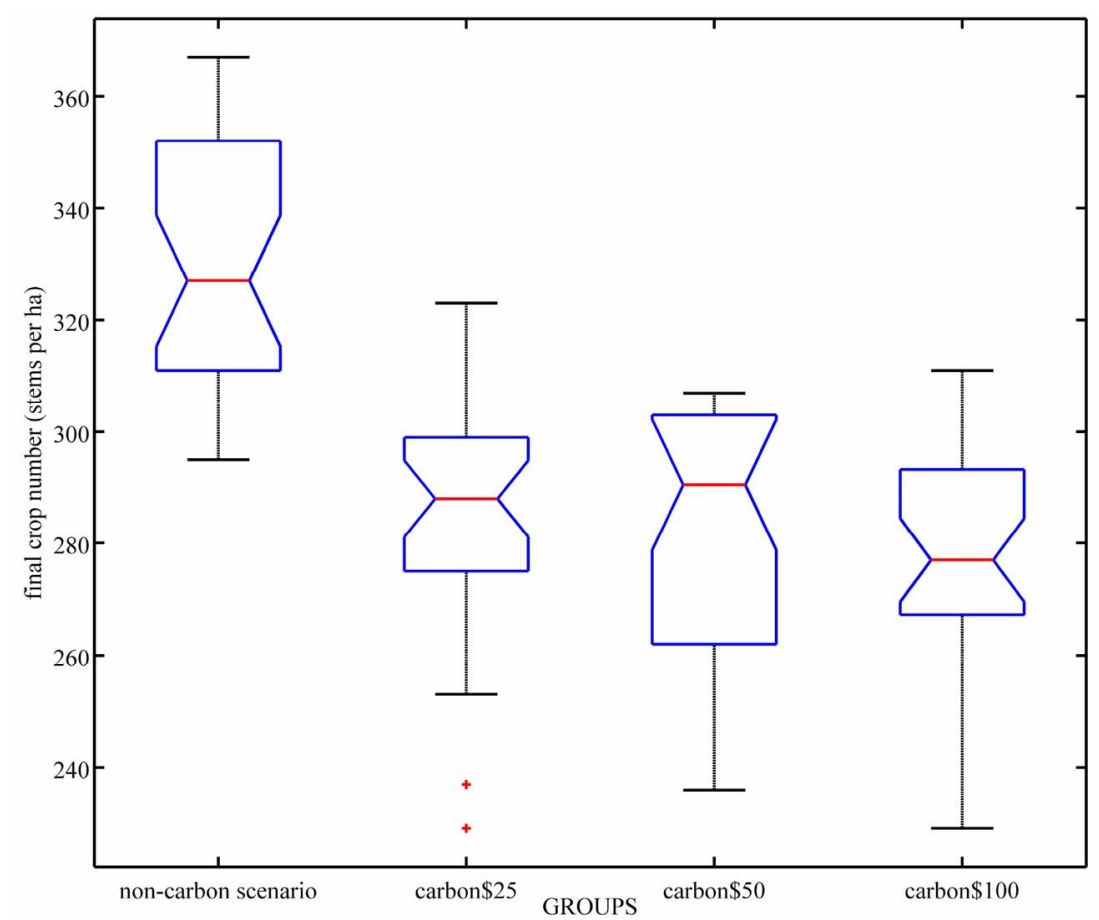

Figure 4.

Box plots of the four scenarios.

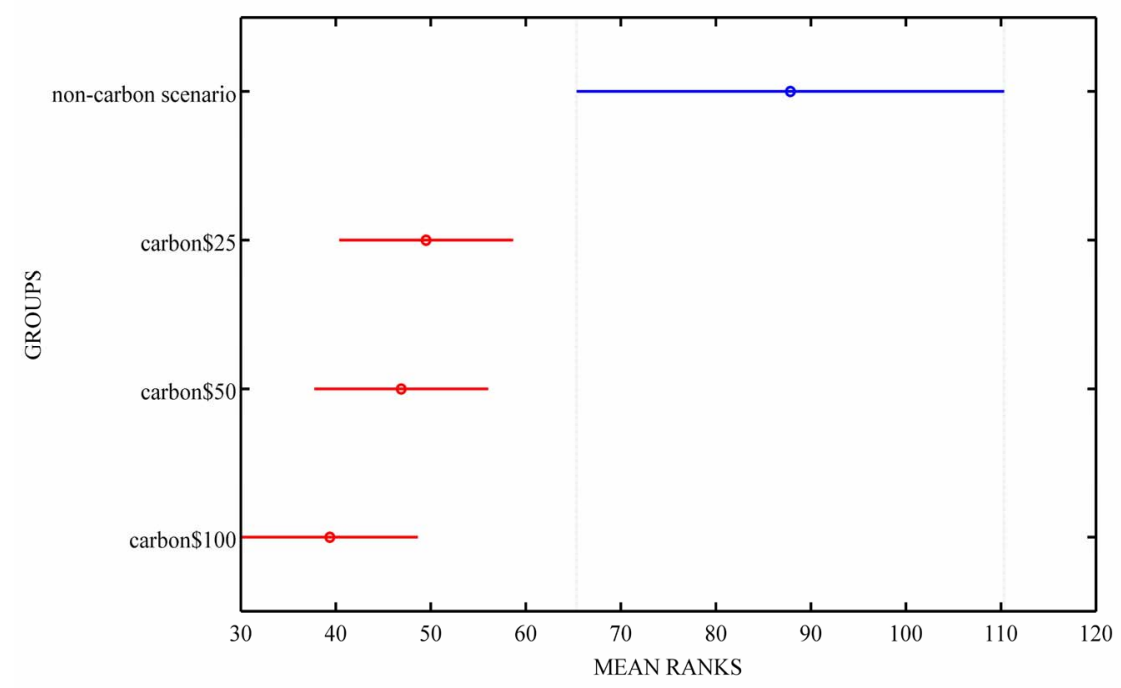

Figure 5.

Wilcoxon rank sum test for the final crop numbers of the different groups/scenarios.

\section{Frequency, Timing and Intensity of Thinning}

The frequency, timing and intensity of thinnings did not show any statistical differences for all the four scenarios. Carbon prices do not seem to influence the thinning strategy where it is already optimized for value and volume productions. This might be explained by the fact that though stand volume is reduced through thinning, the sudden availability of more nutrients, light and moisture to the residual trees boosts their growth. It is this growth that will guarantee more sequestration and possibly more payment. Given that the final crop numbers of all the carbon scenarios were lower than those of the non- carbon scenario, and that the initial planting stockings of all the four scenarios were statistically the same, it therefore stands to confirm this assertion. Also with less number of trees as a final crop, it is possible to keep the trees a little longer than one would normally do in a non-carbon market environment because this may guarantee more growth until full-site occupancy is reached. This might encourage fertilisation following a lateage thinning, in order to boost growth and subsequently sequester more carbon. Implications of late-age fertilisation following a thinning may also mean a premium sawlog/veneer product at the end of the rotation. 


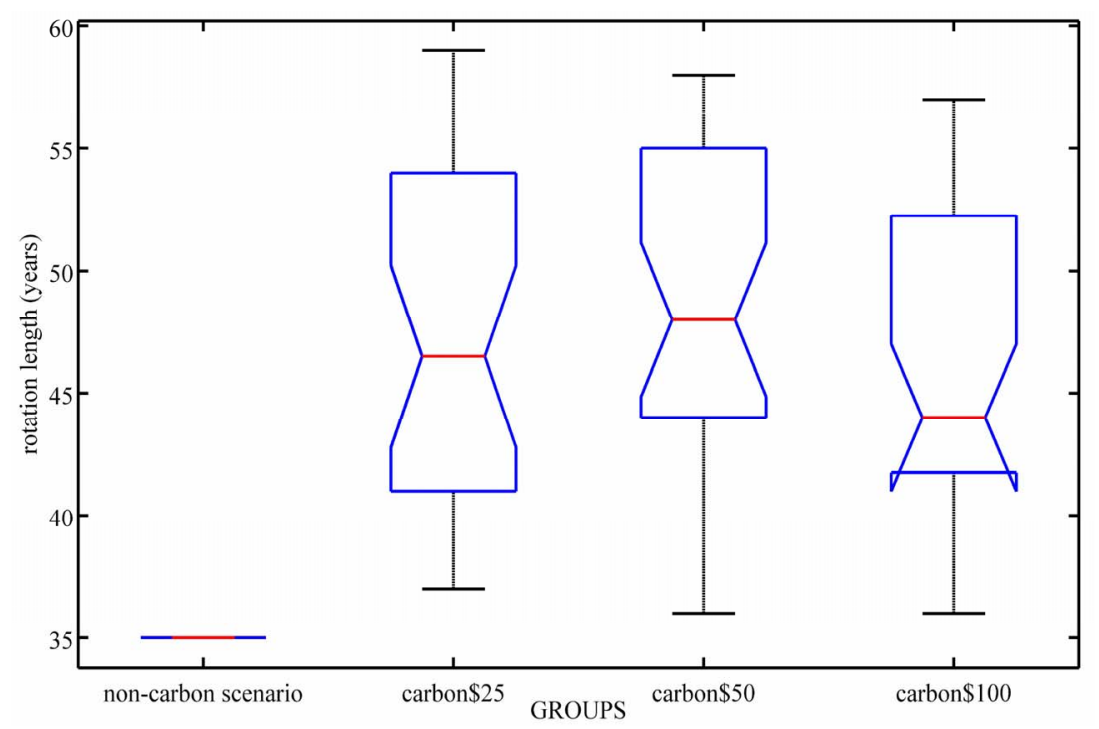

Figure 6.

Box plots of the four scenarios.

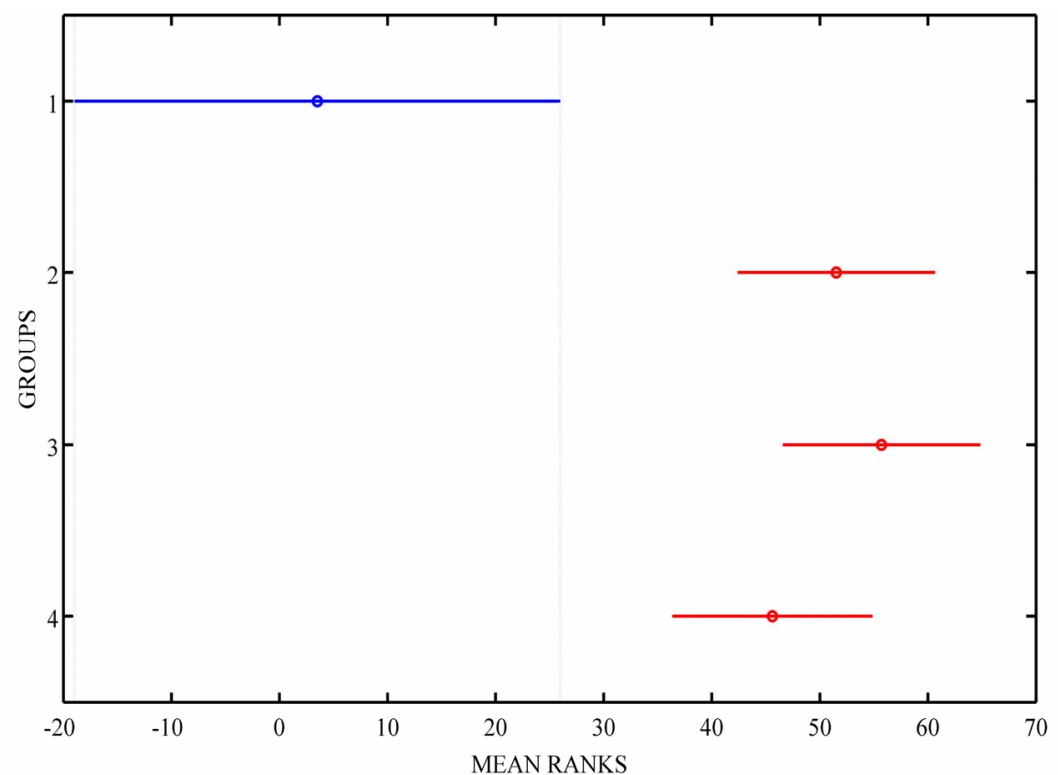

Figure 7.

Wilcoxon rank sum test for the rotation lengths of the different groups/scenarios.

\section{Further Discussion}

These results may have been different if the carbon scenarios were matched with forecasted fluctuations in the prices of liquid fuel and fossil fuel-based fertilisers, as this would have meant changes in the forest holding values. It is difficult to imagine how that would have impacted our results. It may well be that we need to take this research further by developing:

1) A dynamic stumpage model; and

2) A fossil fuel-based fertiliser price model,

under a carbon trading scheme, and revisit our analysis. Both (1) and (2) will expose the forest holding value to a more realistic output, and maybe provide us with further insight into the impact of carbon prices on the silvicultural regimes of $E$. fastigata.
It is important to note that although our results are based on a stand level, they are Pareto sets which can still be used at a forest-estate level, where one has hundreds or thousands of stands at different age classes. With each stand with a Pareto set of possible silvicultural regimes, it is possible to optimise at an estate level, assigning the appropriate regime to each stand, which may mean simultaneously meeting harvesting commitments and optimally sequestering carbon under prevailing market constraints. In other words the Pareto optimality at a stand level gives flexibility at an estate level planning. We have not touched on environmental constraints because of the focus of this paper. However, environmental issues are best dealt with at a forest estate level both temporally and spatially, given their long-term gestation period. 


\section{Conclusion}

The consequences on the silvicultural regimes for Eucalyptus fastigata, when the crop is simultaneously managed for, carbon sequestration, sawlog and pulpwood were, decreased final crop numbers, and increased rotation lengths. It will be well worth it to investigate fertilisation following late-age thinning in order to boost growth. This would mean sequestering more carbon and guarantee of a premium sawlog/veneer product at the end of the rotation. The regimes under a carbon market were also found to be insensitive to fluctuations in the price of carbon. Our findings were based on a fixed stumpage used in the calculation of forest holding values.

\section{Acknowledgements}

This project was funded by the New Zealand Foundation for Research Science and Technology under Contract No. C04X0805, "Diverse Forests" and the contribution from Future Forest Research Ltd is gratefully acknowledged.

\section{REFERENCES}

Appel, D. (2001). Forest rotation lengths under carbon sequestration payments. Conference of Economists, University of Western Australia, Perth. http://129.3.20.41/econ-wp/othr/papers/0110/0110007.pdf

Asante, P., Armstrong, G. W., \& Adamowicz, L. W. (2011). Carbon sequestration and the optimal forest harvest decision: A dynamic programming approach considering biomass and dead organic matter. Journal of Forest Economics, 17, 3-17. doi:10.1016/j.jfe.2010.07.001

Bellman, R. E. (1957). Dynamic programming. Princeton, NJ: Princeton University Press.

Chen, C. M., Rose, D. W., \& Leary R. A. (1980). How to Formulate and solve optimal stand density over time problem for even-aged stands using dynamic programming. General Technical Report NC$56,17 \mathrm{p}$.

Chikumbo, O. (1996). Applicability of dynamical modelling and theoretical control methods in tree growth prediction and planning. Ph.D. Thesis, Canberra: The Australian National University, 273p.

Chikumbo, O. (2009a). An optimal regime model using competitive coevolutionary genetic algorithms. In A. Dourado, A. Rosa, \& K. Madani (Eds.), Proceedings of the International Joint Conference on Computational Intelligence (pp. 210-217). Portugal: Institute for Systems and Technologies of Information, Control and Communication (ISTICC).

Chikumbo, O. (2009b). Exploration and exploitation in function optimization using stochastic generate-and-test algorithms. In H. R. Arabnia, \& A. M. G. Solo (Eds.), Proceedings of the 2009 International Conference on Genetic and Evolutionary Methods (pp. 22-27). Las Vegas, NV: CSREA Press.

Chikumbo, O. (2012). Using different approaches to approximate a Pareto front for a multi-objective evolutionary algorithm: Optimal thinning regimes for Eucalyptus fastigata. International Journal of Forestry Research, 2012, 189081. doi:10.1155/2012/189081

Chikumbo, O., \& Mareels, I. M. Y. (2003). Predicting terminal time and final crop number for a forest plantation stand: Pontryagin's Maxi- mum Principle. In E. Tiezzi, C. A. Brebbia, \& J. L. Uso (Eds.), Ecosystems and sustainable development (pp. 1227-1235). Southampton: WIT Press.

Chikumbo, O., \& Nicholas, I. (2011). Efficient thinning regimes for Eucalyptus fastigata: Multi-objective stand-level optimisation using the island model genetic algorithm, Ecological Modelling, 222, 16831695. doi:10.1016/j.ecolmodel.2011.03.004

Coello, C.A. (1996). An empirical study of evolutionary techniques for multi-objective optimization in engineering design. Ph.D. Thesis, New Orleans, LA: Department of Computer Science, Tulane University.
De Jong, B. H. J., Tipper, R., \& Montoya-Gómez, (2000). An economic analysis of the potential for carbon sequestration by forests: Evidence from southern Mexico. Ecological Economics, 33, pp. 313327. doi:10.1016/S0921-8009(99)00162-7

Faustmann, M. (1995). Calculation of the value which forest land and immature stands possess for forestry. Journal of Forest Economics, 1, 7-44.

Fonseca, C. M., \& Fleming, P. J. (1993). Genetic algorithms for multiple objective optimization: Formulation, discussion and generalizetion. In S. Forrest (Ed.), Proceedings of the Fifth International Conference on Genetics Algorithms, San Mateo, CA: Morgan Kaufmann Publishers.

Gibbons, J. D. (1985). Nonparametric statistical inference (2nd ed.). New York: Marcel Dekker.

Gutrich, J., \& Howarth, R. B. (2007). Carbon sequestration and the optimal management of New Hampshire timber stands. Ecological Economics, 62, 441-450. doi:10.1016/j.ecolecon.2006.07.005

Haslett, A. N. (1988). Properties and utilisation of exotic speciality timber grown in New Zealand. Part V: Ash eucalypts and Eucalyptus nitens. New Zealand Forest Research Institute, FRI Bulletin No. 119, $20 \mathrm{p}$.

Hool, J. N. (1965). A dynamic programming probability approach to forest production control. Social American Forest Proceedings, 191193.

Klemperer, W. D. (1996). Forest resource economics and finance. New York, NY: McGraw-Hill, Inc.

Kruskal W., \& Wallis W. A. (1952). Use of ranks in one-criterion analysis of variance. Journal of the American Statistical Association, $47,583-621$.

Ljung, L. (1987). System identification: Theory for the user. Saddle River, NJ: Prentice Hall.

Malinowska, A. B., \& Torres, D. F. M. (2007). Non-essential functionals in multi-objective optimal control problems. Proceedings of the Estonian Academy of Sciences: Physics \& Mathematics, 56, 336-346.

Mayo J. H., \& Straka T. J. (2005). The holding value premium in standing timber valuation. Appraisal Journal, 73, 98-106.

Meade, R., Fiuza, G., \& Lu, A. (2008). Forest and forest land valuation: How to value forests and forest land to include carbon costs and benefits. Wellington: NZ Institute for the Study of Competition and Regulation Inc., Victoria University of Wellington.

Menczer, F., Degeratu, M., \& Street, W. N. (2000). Efficient and scalable Pareto optimisation by evolutionary local selection algorithms. Evolutionary Computation, 8, 223-247. doi:10.1162/106365600568185

Miller, J. T., Hay, A. E., \& Ecroyd, C. E. (2000). Introduced forest trees in New Zealand: Recognition, role and seed source, Part 18. The Ash Eucalypts: E fastigata, E. regnans, E. obliqua, E. fraxinoides, $E$. delegatensis, E. fraxinoides, E. sieberi, E. oreades, E. pauciflora, E. dendromorpha and E. paliformis. NZFRI Bulletin 124.

Nelder, J. A. (1962). New kinds of systematic designs for spacing experiments. Biometrics, 18, 283-307. doi:10.2307/2527473

Newman D. H., \& Wear D.N . (1993). Production economics of private forestry: A comparison of industrial and nonindustrial forest owners. American Journal of Agricultural Economics, 75, 674-684. doi: $10.2307 / 1243574$

Osborne, M. J., \& Rubenstein, R. (1994). A course in game theory (p. 7). Cambridge, MA: MIT Press.

Polheim, H. (2006). GEATbx: Introduction, evolutionary algorithms: Overview, methods and operators. URL. http://www.geatbx.com

Straka, T. J. \& Bullard S. H. (1996) Land expectation value calculation in timberland valuation. Appraisal Journal, 64, 399-405.

Turner, J.A., West, G., Dungey, H., Wakelin, S., Maclaren, P., Adams, T., \& Silcock, P. (2008). Managing New Zealand planted forests for carbon-A review of selected management scenarios and identification of knowledge gaps, Report by Scion for the New Zealand Ministry of Agriculture and Forestry. Rotorua: Scion.

van Kooten, G. C., Binkley, C. S., \& Delcourt, G. (1995). Effect of carbon taxes and subsidies on optimal forest rotation age and supply of carbon services, American Journal of Agricultural Economics, 77, 365-374. doi:10.2307/1243546

White, A. (2007). Carbon trading outlook: Any additional measures? 
The Bridge magazine, 7, 38-41.

Zitzler, E., Deb, K., \& Thiele, L. (2000). Comparison of multi-objective evolutionary algorithms: Empirical results. Evolutionary Computation, 8, 173-195. doi:10.1162/106365600568202

\section{Appendix A: NZ \$25 Carbon Price Scenario Silvicultural Regimes}

Table A1.

Pareto optimal set for the NZ \$25 carbon price scenario.

\begin{tabular}{|c|c|c|c|c|c|c|c|c|}
\hline REGIME & $\begin{array}{l}\text { Age at } 1^{\text {st }} \\
\text { thinning } \\
\text { (years) }\end{array}$ & $\begin{array}{l}\text { Age at } 2^{\text {nd }} \\
\text { thinning } \\
\text { (years) }\end{array}$ & $\begin{array}{l}\text { Age at } 3^{\text {rd }} \\
\text { thinning } \\
\text { (years) }\end{array}$ & $\begin{array}{c}\text { Clear felling } \\
\text { age } \\
\text { (years) }\end{array}$ & $\begin{array}{c}\text { Initial planting } \\
\text { density } \\
\left(\text { stems } \cdot \mathrm{ha}^{-1}\right)\end{array}$ & $\begin{array}{l}\text { Number thinned } \\
\text { at } 1^{\text {st }} \text { thinning } \\
\left(\text { stems } \cdot \mathrm{ha}^{-1}\right)\end{array}$ & $\begin{array}{l}\text { Number thinned } \\
\text { at } 2^{\text {nd }} \text { thinning } \\
\left(\text { stems } \cdot \mathrm{ha}^{-1}\right)\end{array}$ & $\begin{array}{l}\text { Number thinned } \\
\text { at } 3^{\text {rd }} \text { thinning } \\
\left(\text { stems } \cdot \mathrm{ha}^{-1}\right)\end{array}$ \\
\hline 2 & 8 & 13 & 20 & 43 & 930 & 279 & 188 & 198 \\
\hline 3 & 8 & 15 & 19 & 59 & 924 & 266 & 193 & 188 \\
\hline 4 & 8 & 13 & 20 & 39 & 913 & 274 & 182 & 198 \\
\hline 5 & 8 & 13 & 18 & 39 & 906 & 298 & 178 & 193 \\
\hline 6 & 6 & 15 & 20 & 57 & 973 & 287 & 199 & 178 \\
\hline 7 & 10 & 14 & 19 & 41 & 913 & 287 & 198 & 199 \\
\hline 8 & 6 & 14 & 21 & 37 & 937 & 267 & 168 & 197 \\
\hline 9 & 7 & 15 & 21 & 39 & 968 & 270 & 195 & 180 \\
\hline 10 & 7 & 12 & 19 & 39 & 960 & 296 & 187 & 178 \\
\hline 11 & 6 & 14 & 21 & 54 & 937 & 278 & 162 & 195 \\
\hline 12 & 5 & 15 & 19 & 47 & 937 & 291 & 188 & 174 \\
\hline 13 & 5 & 12 & 21 & 46 & 934 & 286 & 194 & 168 \\
\hline 14 & 6 & 14 & 18 & 59 & 925 & 298 & 184 & 150 \\
\hline 15 & 5 & 14 & 20 & 52 & 915 & 273 & 182 & 170 \\
\hline 16 & 5 & 13 & 19 & 47 & 935 & 273 & 200 & 187 \\
\hline 17 & 7 & 12 & 21 & 46 & 946 & 292 & 189 & 165 \\
\hline 18 & 6 & 15 & 21 & 57 & 912 & 283 & 193 & 137 \\
\hline 20 & 6 & 12 & 21 & 51 & 921 & 265 & 173 & 189 \\
\hline 21 & 5 & 13 & 19 & 44 & 939 & 261 & 199 & 200 \\
\hline 22 & 5 & 15 & 21 & 57 & 905 & 294 & 125 & 196 \\
\hline 23 & 5 & 15 & 19 & 58 & 903 & 264 & 182 & 187 \\
\hline 24 & 7 & 14 & 19 & 46 & 938 & 274 & 195 & 178 \\
\hline 25 & 7 & 14 & 21 & 48 & 927 & 236 & 183 & 189 \\
\hline 26 & 7 & 15 & 20 & 39 & 913 & 295 & 177 & 155 \\
\hline 27 & 7 & 12 & 19 & 42 & 921 & 264 & 181 & 198 \\
\hline 28 & 7 & 15 & 20 & 39 & 913 & 295 & 177 & 155 \\
\hline 29 & 7 & 15 & 20 & 59 & 916 & 231 & 194 & 186 \\
\hline 30 & 7 & 13 & 20 & 48 & 908 & 283 & 133 & 193 \\
\hline
\end{tabular}


Appendix B: NZ \$50 Carbon Price Scenario Silvicultural Regimes

Table B1.

Pareto optimal set for the NZ $\$ 50$ carbon price scenario.

\begin{tabular}{|c|c|c|c|c|c|c|c|c|}
\hline REGIME & $\begin{array}{l}\text { Age at } 1^{\text {st }} \\
\text { thinning } \\
\text { (years) }\end{array}$ & $\begin{array}{l}\text { Age at } 2^{\text {nd }} \\
\text { thinning } \\
\text { (years) }\end{array}$ & $\begin{array}{l}\text { Age at } 3^{\text {rd }} \\
\text { thinning } \\
\text { (years) }\end{array}$ & $\begin{array}{c}\text { Clear } \\
\text { felling age } \\
\text { (years) }\end{array}$ & $\begin{array}{c}\text { Initial planting } \\
\text { density } \\
\left(\text { stems } \cdot \mathrm{ha}^{-1}\right)\end{array}$ & $\begin{array}{c}\text { Number thinned at } \\
1^{\text {st }} \text { thinning } \\
\left(\text { stems } \cdot h^{-1}\right)\end{array}$ & $\begin{array}{l}\text { Number thinned at } \\
2^{\text {nd }} \text { thinning } \\
\left(\text { stems } \cdot \text { ha }^{-1}\right)\end{array}$ & $\begin{array}{l}\text { Number thinned } \\
\text { at } 3^{\text {rd }} \text { thinning } \\
\left(\text { stems } \cdot \text { ha }^{-1}\right)\end{array}$ \\
\hline 1 & 6 & 13 & 19 & 53 & 912 & 283 & 182 & 192 \\
\hline 2 & 5 & 15 & 20 & 44 & 917 & 299 & 200 & 164 \\
\hline 3 & 7 & 12 & 20 & 47 & 954 & 299 & 198 & 197 \\
\hline 4 & 7 & 14 & 19 & 48 & 920 & 299 & 189 & 191 \\
\hline 5 & 7 & 12 & 19 & 58 & 911 & 260 & 197 & 197 \\
\hline 6 & 7 & 13 & 21 & 58 & 900 & 278 & 195 & 191 \\
\hline 7 & 7 & 13 & 20 & 46 & 909 & 262 & 198 & 185 \\
\hline 8 & 6 & 15 & 21 & 55 & 970 & 292 & 186 & 185 \\
\hline 9 & 6 & 15 & 21 & 55 & 970 & 292 & 186 & 185 \\
\hline 10 & 6 & 14 & 20 & 38 & 944 & 256 & 197 & 187 \\
\hline 11 & 7 & 12 & 18 & 51 & 941 & 276 & 196 & 178 \\
\hline 12 & 6 & 15 & 20 & 46 & 937 & 273 & 166 & 195 \\
\hline 13 & 5 & 15 & 19 & 53 & 946 & 292 & 150 & 198 \\
\hline 14 & 5 & 13 & 20 & 52 & 938 & 294 & 166 & 185 \\
\hline 15 & 5 & 14 & 21 & 56 & 933 & 293 & 192 & 156 \\
\hline 16 & 5 & 14 & 20 & 48 & 986 & 296 & 200 & 196 \\
\hline 17 & 5 & 12 & 21 & 52 & 943 & 287 & 198 & 167 \\
\hline 18 & 5 & 15 & 18 & 47 & 916 & 289 & 194 & 158 \\
\hline 19 & 5 & 13 & 19 & 56 & 909 & 298 & 175 & 174 \\
\hline 20 & 5 & 15 & 19 & 44 & 964 & 282 & 194 & 200 \\
\hline 21 & 5 & 13 & 19 & 40 & 916 & 281 & 176 & 198 \\
\hline 22 & 6 & 12 & 19 & 46 & 931 & 281 & 172 & 183 \\
\hline 23 & 6 & 14 & 19 & 44 & 931 & 258 & 192 & 176 \\
\hline 24 & 6 & 15 & 20 & 36 & 901 & 297 & 167 & 164 \\
\hline 25 & 6 & 13 & 19 & 48 & 912 & 292 & 169 & 185 \\
\hline 26 & 5 & 15 & 20 & 57 & 901 & 275 & 146 & 190 \\
\hline 27 & 5 & 14 & 19 & 38 & 901 & 231 & 180 & 186 \\
\hline 28 & 6 & 15 & 19 & 51 & 900 & 283 & 127 & 189 \\
\hline 29 & 5 & 15 & 20 & 57 & 907 & 225 & 183 & 192 \\
\hline 30 & 6 & 15 & 21 & 38 & 911 & 245 & 186 & 197 \\
\hline
\end{tabular}




\section{Appendix C: NZ \$100 Carbon Price Scenario Silvicultural Regimes}

Table C1.

Pareto optimal set for the NZ \$100 carbon price scenario.

\begin{tabular}{|c|c|c|c|c|c|c|c|c|}
\hline REGIME & $\begin{array}{l}\text { Age at } 1^{\text {st }} \\
\text { thinning } \\
\text { (years) }\end{array}$ & $\begin{array}{l}\text { Age at } 2^{\text {nd }} \\
\text { thinning } \\
\text { (years) }\end{array}$ & $\begin{array}{l}\text { Age at } 3^{\text {rd }} \\
\text { thinning } \\
\text { (years) }\end{array}$ & $\begin{array}{c}\text { Clear felling } \\
\text { age } \\
\text { (years) }\end{array}$ & $\begin{array}{c}\text { Initial planting } \\
\text { density } \\
\left(\text { stems } \cdot \mathrm{ha}^{-1}\right)\end{array}$ & $\begin{array}{l}\text { Number thinned } \\
\text { at } 1^{\text {st }} \text { thinning } \\
\left(\text { stems } \cdot \mathrm{ha}^{-1}\right)\end{array}$ & $\begin{array}{l}\text { Number thinned } \\
\text { at } 2^{\text {nd }} \text { thinning } \\
\left(\text { stems } \cdot \mathrm{ha}^{-1}\right)\end{array}$ & $\begin{array}{l}\text { Number thinned } \\
\text { at } 3^{\text {rd }} \text { thinning } \\
\left(\text { stems } \cdot \mathrm{ha}^{-1}\right)\end{array}$ \\
\hline 2 & 6 & 13 & 21 & 42 & 915 & 294 & 198 & 194 \\
\hline 3 & 7 & 14 & 18 & 49 & 921 & 289 & 198 & 182 \\
\hline 4 & 7 & 14 & 19 & 43 & 907 & 272 & 195 & 200 \\
\hline 5 & 8 & 15 & 19 & 46 & 941 & 285 & 200 & 182 \\
\hline 6 & 7 & 14 & 21 & 51 & 903 & 254 & 189 & 191 \\
\hline 7 & 8 & 15 & 19 & 44 & 912 & 278 & 179 & 190 \\
\hline 9 & 6 & 15 & 19 & 47 & 960 & 291 & 200 & 182 \\
\hline 10 & 7 & 15 & 19 & 40 & 999 & 300 & 200 & 197 \\
\hline 11 & 5 & 12 & 21 & 50 & 947 & 288 & 193 & 197 \\
\hline 12 & 5 & 14 & 18 & 53 & 942 & 296 & 196 & 189 \\
\hline 13 & 5 & 14 & 20 & 56 & 940 & 273 & 184 & 190 \\
\hline 14 & 6 & 12 & 19 & 36 & 932 & 283 & 183 & 189 \\
\hline 15 & 5 & 14 & 21 & 36 & 930 & 269 & 176 & 191 \\
\hline 16 & 5 & 12 & 20 & 42 & 924 & 282 & 177 & 180 \\
\hline 17 & 6 & 13 & 21 & 37 & 915 & 298 & 165 & 184 \\
\hline 19 & 7 & 15 & 18 & 50 & 958 & 289 & 181 & 194 \\
\hline 20 & 5 & 12 & 19 & 44 & 913 & 243 & 185 & 199 \\
\hline 21 & 6 & 12 & 18 & 56 & 902 & 294 & 174 & 152 \\
\hline 22 & 5 & 12 & 19 & 57 & 919 & 296 & 177 & 177 \\
\hline 23 & 6 & 15 & 21 & 53 & 922 & 222 & 198 & 191 \\
\hline 24 & 6 & 13 & 21 & 41 & 901 & 287 & 147 & 194 \\
\hline 25 & 5 & 13 & 20 & 38 & 908 & 237 & 169 & 200 \\
\hline 26 & 5 & 13 & 21 & 42 & 918 & 231 & 197 & 193 \\
\hline 27 & 6 & 14 & 19 & 43 & 915 & 243 & 198 & 195 \\
\hline 28 & 6 & 15 & 19 & 53 & 912 & 260 & 182 & 167 \\
\hline 29 & 5 & 15 & 18 & 53 & 903 & 257 & 193 & 180 \\
\hline
\end{tabular}

